venture to think the metallurgists have done their lart ; we can tell you how to produce all these things mains for your artist to employ them.

In conclusion, I would say that many of these al loys miav be blended by casting : you way have an alloy
with a solidifying point a little lower than the rest. and pour the two alloys in succession, and the one which sets first may be covered by the other one.
Here is an exiluple of a bronze god (Fig. 12) clothed in brass, with brass anklets and bracelets. That is done hy pouring brass round a copper casting of suitable
form. (On slicing this figure through, we found that was the fact. You have here the copper covered by in this way by pouring alloys one over the other.

in this way by pouring alloys one over the other.
While this paper is passing through the press an ex-
cellent exhibition of metal work has been opened in cellent exhibition of metal work has been opened in London, the Arwourers' and Braziers' Company. 'The works exhibited showed no lack of inventive power and careful design, notably in the case of the articles
sent by the East-end "Guild and School of Handicraft," but the craftsmen limited their efforts to working in brass, copper, iron and the precious metals, and appeared to have no notion that a wide range of beaushould be made to induce British artificers to employ thren have used for centuries with such remarkable effect.

\section{A CHEAP FUNNEL-JACKET}

By John A. Forret.

THE appliances in the market for keeping solutions hot while being filtered are a water-jacket of tin or bath. With the tin-jacket there is no means of dryiug it after use, which means rapid corrosion by rust, while the copper article is too expensive. The only objection I have to the water-bath jacket is the large
quantity of water to be heated when the bath is used quantity of wate

for filtering alone. I devised the hot-funnel shown in
Sowe time ago I section below, and find it to answer the purposes of a

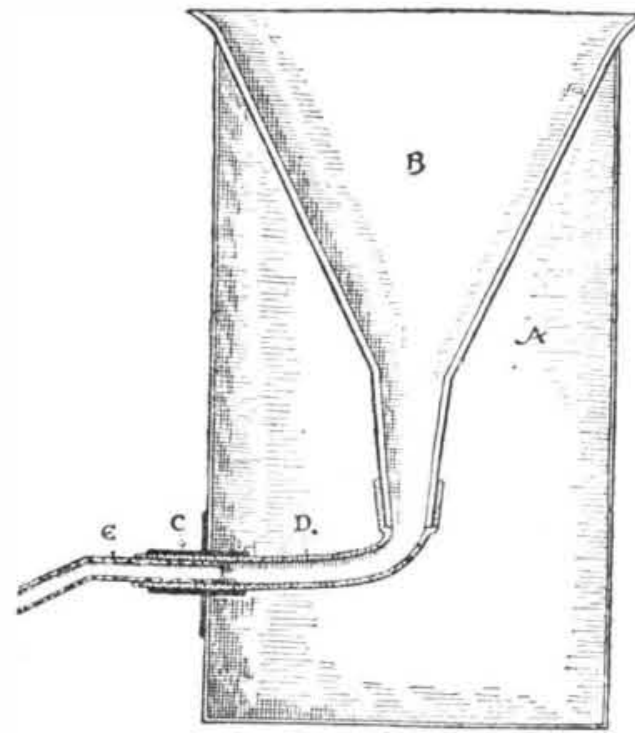

$A$, tin box, round or square; $B$, funnel; $C$, brass tube, with collar soldered into $A ; D$, I. R. tubing,
stretched over funnel and fitting accurately into $\mathrm{C}$ $\mathrm{E}$, glass tube titting tightly into $\mathrm{D}$.

hot-water funnel-jacket. The funnel being in direct rapidly heated than in the case of the ordinary jacket, with its intervening tin or copper. One drawback, however, is its fixity when in use-the funnel cannot be removed without emptying the bath. The whole thing can be put together in the back shop at the expense of a little time and patience. The the brass tube being the neck of a disused spirit-lawp. -Chemist and Druggist.

WIBORGH'S METHOD FOR THE ANALYSIS OF SULPHUR IN IRON AND STEEL. By J. B. Cohen, Ph.D.

THIs method, which has recently been published in detail in Prof essor Ledebur's new volume on iron and steel analysis (Leitfaden fur Eisenhutten-Laborato-
rien: Vieweg und Sohn), is described as rapid and accurate. The apparatus is shown in the figure.
It consists of a wide necked flask, $a$, of $250-300 \mathrm{cc}$

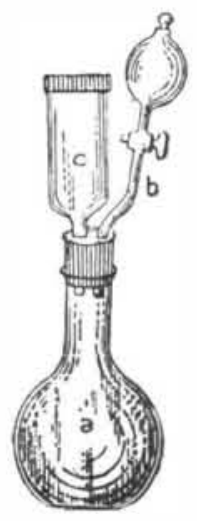

capacity, to which is fitted a double bored cork Through one hole passes a tap funnel, $b$, which tera cylindrical glass tube, $c$, about 21 crn. long, open at ter, and the lower end drawn out so as to pass through the second hole in the cork. The amount of sulphur is by $\mathrm{H}_{2} \mathrm{~S}$ on the surface of a piece of calico previously soaked in a 5 per cent. cadmium acetate solution an
dried, the calico being stretched across the wide ope dried, the calico being stretched across the wide ope
end of the cylindrical tube. The calico may be

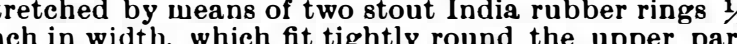
of the wide tube. One ring is allowed to project above the tube, so as to form a horizontal edge, and over this the calico is stretched by means of the second ring.
Ledebur employs a wooden ring and two clamps, but Ledebur employs a wooden ring and two clamps, but
he above method answers perfectly well. The flask is first half filled with water and boiled on a sand bath to expel air, the sample of iron or steel,
0.1 to 0.8 grim. according to the amount of sulphur, is
quickly introduced, and the water again boiled for a few winutes ; dilute sulphuric acid $(1: 5)$ is introduced
from the tap funnel gradually until the iron is dissolvwithout interrupting the heating.

Sulphureted hydrogen is evolved and the calico is the obtain an even stain it is necessary that When the iron is completely dissolved, the boilin. continued for eight to ten minutes. The calico is now removed, well rinsed and dried, and the stain compared with a set of standard colors. The set of stand-
ards (six shades are sufficient) is prepared by taking a ards (six shades are sufficient) is prepared by taking a obtaining various shades with different weights of the sample by the method described above. These should be mounted on white cardboard and kept for compariHaving made an analysis and fixed upon the stand ard shade which comes nearest to that of the sample ormula: nd $w_{1}$ is the weight of the sample taken, then the weight of sulphur $s_{1}$ in the sample is

$$
s_{1}=\frac{w s}{w_{1}}
$$

The same standard shade can therefore be used for variety of samples when different
ployed.-Jour. Soc. Chem. Inclustry.

\section{THE SCIENTIFIC AMERICAN Architectsand Builders Edition.}

\section{$\$ 2.50$ a Year. Single Copies, 25 cts.}

This is a Special Edition of the ScIENTIFIC AMRRIEach number contains about forty large quarto pages. equal to about two hundred ordinary book pages, forming, practically, a large ind splendid Magazine in colers and with fine adoravings, illustrating th most interesting examples of modern Architectura

A special feature is the presentation in each number residences, city and country, including those of very ings in perspective and in color are given, together ith full Plans, Specifications, Costs, Bills of Estimate. No other building

作 SCIEN'IrIC AMERICAN. Hundreds of dwellings have already been erected on the various plans we have process of construction. year, and wany others are in process of construction.
Architects, Builders, and Owners will find this work aluable in furnishing fresh and useful suggestions recting structures of any kind, have before them, in this work an almost endless series of the latest and bes Many other subjects, including Sewerage, Piping,
time and inome Many other subjects, including Sewerage, Piping
Lighting. Warming, Ventilating, Decorating, Laying out of Grounds, etc., are illustrated. An extensive given, in which the wost reliable and approved Buildare described and illustrated, with addresses of the makers, etc.

The fullness, richness, cheapness, and convenience of
this work have won for it the Largest Circulation of any Architectural publication in the world.

A Catalogue of valuable books on Architecture, Lighting, Ventilation, and all branches of industry pertaining to the art of Building, is supplied free of charge, sent to any address.

MUN \& CO., Publishers, 361 Broadway, New York.

Building Plans and Specifications.

In connection with the publication of the BuILDING EDITION of the SCIENTIFIC AMERICAN, Messrs. Munn \& Co. furnish plans and specifications for buildings
of every kind, including Churches, Schools, Stores, Dwellings, Carriage Houses, Barns, etc.

In this work they are assisted by able and experitions fcr the various buildings illustrated in this paper

Those who contemplate building, or who wish to
can be suplied. alter, improve, extend, or add to existing buildings, whether wings, porches, bay windows, or attic rooms,
are invited to communicate with the undersigned Our work extends to all parts of the country. Estimates, plans, and drawings promptly prepared. Term moderate. Address

MUNN \& CO., 361 BROAdWAY, NEW YORK.
T巫上

\section{Scientific American Supplement.}

PUBLISHED WEEKLY.

Tarms of Subscription, $\$ 5$ a year.

Sent by mail, postage prepaid, to subseribers in any ar, sent, prepaid, to any foreign country. commencement, January 1, 1876, can be had, Prom the 10 cents each.

All the back volumes of Thr SuPPLEMENT can likewise be supplied. Two volumes are issued yearly.
Price of each volume, $\$ 2.50$ stitched in paper, or $\$ 3.50$ CombINED RATrs. AN and one copy of ScinnTry MKNT, one year, postpaid, \$7.00.
A liberal discount to booksellers, news agents, and MUNN \& CO., Publishers,

361 Broadway, Now York, N. y.

TABLE OF CUNTENTB.

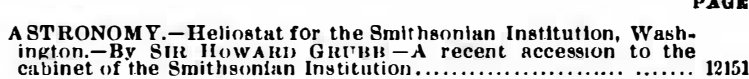
II. CHEMISTRY.-A Cheap Funnel Jacket-By Johv A. Fonker.

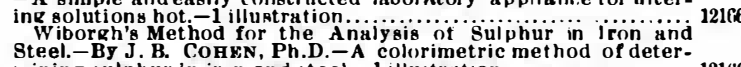

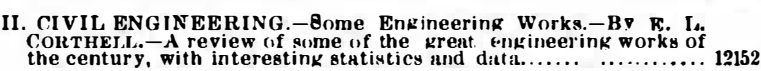

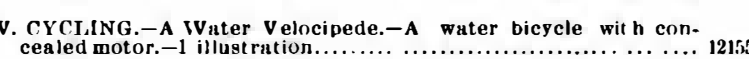

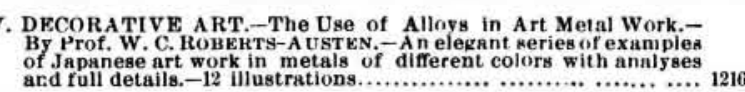
ard full details, -12 illustrations............................... trationsof parts.-12 illustrations................................... 1210

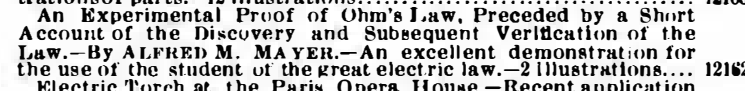

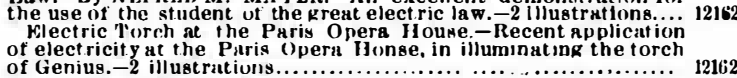

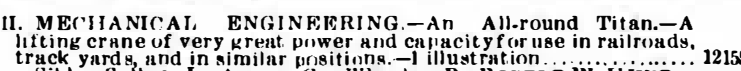

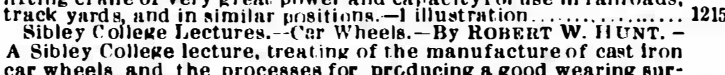

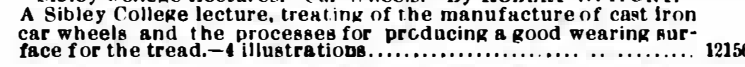
VIII. MISCELLI.ANEOUS.-IIIlingolund.-Description of the island
recently ceded to Germany by Enkland....................... 1215:

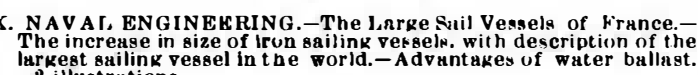

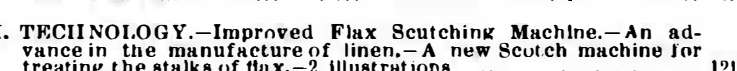

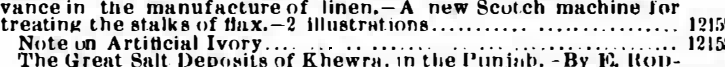

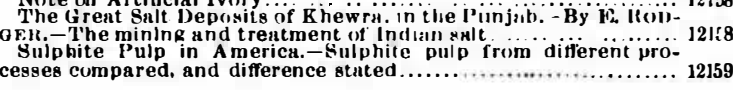
A Now Catalograe of Valandbe Papers

Contained in Scientific American Supplament during the past ten years, sent free of eharge to any
address. MUNN \& CO., 361 Broadway, New York.

\section{Useful Engineering Books}

Manufacturers, Agriculturists, Chemists, Engineers wen, of all classes, need good books in the line of their respective callings. Our post office department perwit the transmission of books through the mails at very by different authors, on more than fifty different subjects, has recently been published, for free circulation at the office of this paper. Subjects classified with to ask for it, and it will be mailed to them. Address,

MUNN \& CO., 361 Broadway, New York

\section{PATENTS.}

In connection with the Scientific American Messrs. MUNN \& Co. are solicitors of American an oreign Patents, have had 42 years' experience, and Patents are obtained on the best terms.
A special notice is wade in the Scientific American of all inventions patented through this Agency,
with the name and residence of the Patente. By the with the name and residence of the Patentee. By the directed to the merits of the new patent, and sales or Any person who has made a new covery or invencan probably be obtained, by writing to M MN \& \& Co We also send free our Hand Book about the Paten Laws, Patents, Caveats, Trade Marks, their costs and

MUIJI de OO., 361 Broadway, New York.

Branch Omce, 622 and 624 F St., Washington, D. C. 